Pacific Journal of Mathematics

SEMIGROUPS OF MATRICES DEFINING LINKED
OPERATORS WITH DIFERENT SPECTRA 


\title{
SEMIGROUPS OF MATRICES DEFINING LINKED OPERATORS WITH DIFFERENT SPECTRA
}

\author{
Charles J. A. Halberg, Jr.
}

1. Introduction. The concept of "linked operators" was introduced by A. E. Taylor and the author in [1]. This concept was originally suggested by work involving bounded linear operators on the sequence spaces $l_{p}$. For example, if the infinite matrix $\left(t_{i j}\right)$ defines operators $T_{p}$ and $T_{q}$ that are bounded on $l_{p}$ and $l_{q}$, respectively, then these operators are linked. The somewhat complicated general definition of linked operators is deferred until $\S 2$ of this paper. In [1] an isolated, specific example of linked operators with different spectra was given. The purpose of this paper is to exhibit three infinite semigroups of infinite matrices $\left(t_{i j}\right)$, with complex coefficients, such that each of their elements defines linked operators with different spectra.

In the next section we give some preliminary definitions and notation and in the final section we prove a basic lemma and our principal theorems.

2. Preliminary definitions and notation. We first give the definition of linked operators.

Definition. Let $X, Y$ be complex linear spaces, and $Z$ a non-void complex linear space contained in both $X$ and $Y$. Let $X$ be a Banach space $X_{1}, Y$ a Banach space $Y_{2}$ under the norms $n_{1}, n_{2}$ respectively. Let $Z$ be a Banach space $Z_{N}$ under the norm $N$ defined by $N(z)=$ $\max \left[n_{1}(z), n_{2}(z)\right]$. With the usual uniform norms let $T_{1}, T_{2}$ be bounded linear operators on $X_{1}, Y_{2}$ respectively, such that $T_{1} z=T_{2} z \in Z$ when $z \in Z$. Operators satisfying these conditions are said to be "linked."

Our basic notation will be as follows: If $T$ denotes the infinite matrix $\left(t_{i j}\right)$, with complex coefficients, then $T^{t}$ will denote its transpose, and $\bar{T}$ the matrix $\left(\bar{t}_{i j}\right)$, where $\bar{z}$ is the complex conjugate of $z$. Let $T_{p}$ denote the operator defined on $l_{p}$ by the matrix $T$, $\left\|T_{p}\right\|$ its norm, and $\left[l_{p}\right]$ the algebra of bounded linear operators on $l_{p}$. Also let $\rho\left(T_{p}\right)$ denote the resolvent set of $T_{p}$, consisting of all complex $\lambda$ such that $\lambda I-T_{p}$ defines a one-to-one correspondence of $l_{p}$ onto $l_{p} ; \sigma\left(T_{p}\right)$ denote the spectrum of $T_{p}$, consisting of all $\lambda$ not in $\rho\left(T_{p}\right)$; and $\left|\sigma\left(T_{p}\right)\right|$ the spectral radius of $T_{p}$.

The matrix $\left(t_{i j}\right)$ is said to be "regular" in case for every convergent. sequence $\left[\zeta_{n}\right], \lim _{n \rightarrow \infty} \zeta_{n}=\zeta$, each of the series $\sum_{k=1}^{\infty} t_{i k} \zeta_{k}$ is convergent.

Received December 6, 1962. Part of the work done on this paper was carried on while the author was an NSF Fellow, visiting at the University of Copenhagen, Denmark. 
and $\lim _{i \rightarrow \infty} \sum_{k=1}^{\infty} t_{i k} \zeta_{k}=\zeta$. It is well known that a set of necessary and sufficient conditions for a matrix to be regular are:

$$
\begin{gathered}
\sup _{i} \sum_{k=1}^{\infty}\left|t_{i k}\right|<\infty \\
\lim _{i \rightarrow \infty} t_{i k}=0 \text { for } k=1,2, \cdots \\
\lim _{i \rightarrow \infty} \sum_{k=1}^{\infty} t_{i k}=1 .
\end{gathered}
$$

\section{Principal theorems.}

Lemma. Suppose that $C=\left(c_{i j}\right)$ and $D=\left(d_{i j}\right)$ define elements of $\left[l_{1}\right]$, and $C^{t} /\left\|C_{1}\right\|$ and $D^{t} /\left\|D_{1}\right\|$ are regular. Then $(C D)^{t} /\left\|(C D)_{1}\right\|$ is regular and $\left\|(C D)_{1}\right\|=\left\|C_{1}\right\|\left\|D_{1}\right\|$.

Proof. Since the product of regular matrices exists and is regular, we have,

$$
\lim _{i \rightarrow \infty} \sum_{j=1}^{\infty} \sum_{k=1}^{\infty} \frac{d_{i k}^{t}}{\left\|D_{1}\right\|} \frac{c_{k j}^{t}}{\left\|C_{1}\right\|}=1
$$

whence,

$1=\lim _{i \rightarrow \infty}\left|\sum_{j=1}^{\infty} \sum_{k=1}^{\infty} \frac{d_{i k}^{t} c_{k j}^{t}}{\left\|D_{1}\right\|\left\|C_{1}\right\|}\right| \leqq \varlimsup_{i \rightarrow \infty} \sum_{j=1}^{\infty}\left|\sum_{k=1}^{\infty} \frac{c_{j k} d_{k i}}{\left\|C_{1}\right\|\left\|D_{1}\right\|}\right| \leqq \frac{\|(C D)_{1} \mid}{\left\|C_{1}\right\|\left\|D_{1}\right\|} \leqq 1$.

Therefore $\left\|(C D)_{1}\right\|=\left\|C_{1}\right\|\left\|D_{1}\right\|$, and $D^{t} C^{t} /\left\|D_{1}\right\|\left\|C_{1}\right\|=(C D)^{t} /\left\|(C D)_{1}\right\|$ is regular. The following result is a simple consequence of this lemma, coupled with the well known fact that

$$
\lim _{n \rightarrow \infty}\left\|T^{n}\right\|^{1 / n}=|\sigma(T)| \text {, }
$$

whenever $T \in[X]$, where $X$ is a complex Banach space.

Corollary. If $T \in\left[l_{1}\right]$ and $T^{t} /\left\|T_{1}\right\|$ is regular, then $\left|\sigma\left(T_{1}\right)\right|=\left\|T_{1}\right\|$.

We are now ready for our principal theorems.

THEOREM 1. Suppose that both $T=\left(t_{i j}\right)$ and $T^{t}=\left(t_{i j}^{t}\right)$ define elements of $\left[l_{1}\right], \quad T^{t} /\left\|T_{1}\right\|$ is regular, and $\left\|T_{1}^{t}\right\|<\left\|T_{1}\right\|$. Then $\left|\sigma\left(T_{1}\right)\right|>\left|\sigma\left(T_{p}\right)\right|, p>1$.

Proof. Using the fact that the spectral radius of an operator is less than or equal to its norm, and the special case where $q=1$, of the inequality

$$
\left\|T_{p}\right\| \leqq\left\|T_{q}\right\|^{(q+p(1-q)) /(2-q) p}\left\|\left(T^{t}\right)_{q}\right\|^{(p-q) /(2-q) p},
$$


$p$ between $q$ and $q^{\prime}$, (which in turn is a special case of a more general inequality, (2), p. 729 in [2]), we see that

$$
\left|\sigma\left(T_{p}\right)\right| \leqq\left\|T_{p}\right\| \leqq\left\|T_{1}\right\|^{1 / p}\left\|T_{1}^{t}\right\|^{1-1 / p} .
$$

Since by hypothesis $\left\|T_{1}^{t}\right\|<\left\|T_{1}\right\|$, it follows immediately that $\left|\sigma\left(T_{p}\right)\right|<\left\|T_{1}\right\|$. But since by since by hypothesis $T^{t} /\left\|T_{1}\right\|$ is regular, we have by our corollary that $\left\|T_{1}\right\|=\left|\sigma\left(T_{1}\right)\right|$, and our theorem is proved.

One might wonder if the result of Theorem 1 is perhaps attributable to the "lopsided" nature of the matrix; that is, the property that the supremum of the $l_{1}$ norms of the column vectors is greater than that of the row vectors. The following theorem demonstrates that is not the case.

TheOREM 2. Suppose that both $T /\left\|T_{1}^{t}\right\|$ and $T^{t} /\left\|T_{1}\right\|$ are regular and that $\left\|T_{1}^{t}\right\|<\left\|T_{1}\right\|$. Then $A=\bar{T}^{t}+T$ is a hermitian symmetric matrix such that $\left|\sigma\left(A_{p}\right)\right|<\left|\sigma\left(A_{1}\right)\right|, 1<p<\infty$.

Proof. The assumptions of regularity guarantee that

$$
\lim _{j \rightarrow \infty} \sum_{i=1}^{\infty} t_{i j}=\left\|T_{1}\right\| \text { and } \lim _{j \rightarrow \infty} \sum_{i=1}^{\infty} t_{\imath j}^{t}=\lim _{j \rightarrow \infty} \sum_{i=1}^{\infty} \overline{t_{i j}^{t}}=\left\|T_{1}^{t}\right\| \text {. }
$$

Thus we see that

$$
\left\|T_{1}\right\|+\left\|\bar{T}_{1}^{t}\right\| \geqq\left\|T_{1}+\bar{T}_{1}^{t}\right\| \geqq \lim _{j \rightarrow \infty} \sup \left|\sum_{i=1}^{\infty}\left(t_{i j}+t_{i j}^{t}\right)\right|=\left\|T_{1}\right\|+\left\|T_{1}^{t}\right\|,
$$

whence $\left\|T_{1}+\bar{T}_{1}^{t}\right\|=\left\|T_{1}\right\|+\left\|T_{1}^{t}\right\|$.

Now

$$
\begin{aligned}
\left\|T_{p}+\bar{T}_{p}^{t}\right\| & \leqq\left\|T_{p}\right\|+\left\|\bar{T}_{p}^{t}\right\|=\left\|T_{p}\right\|+\left\|T_{p}^{t}\right\| \\
& \leqq\left\|T_{1}\right\|^{1 / p}\left\|T_{1}^{t}\right\|^{1-(1 / p)}+\left\|T_{1}^{t}\right\|^{1 / p}\left\|T_{1}\right\|^{1-(1 / p)},
\end{aligned}
$$

the last inequality being a result of (A) above. We shall now show that the right hand member of this inequality is less than $\left\|T_{1}\right\|+\left\|T_{1}^{t}\right\|$.

From the hypothesis that $\left\|T_{1}^{t}\right\|<\left\|T_{1}\right\|$, we can conclude that $\left\|T_{1}\right\|^{1 / p}-\left\|T_{1}^{t}\right\|^{1 / p}>0$ and $\left\|T_{1}^{t}\right\|^{1-(1 / p)}-\left\|T_{1}\right\|^{1-(1 / p)}<0$ for $1<p<\infty$. It is now an immediate consequence that

$$
\begin{aligned}
0 & >\left(\left\|T_{1}\right\|^{1 / p}-\left\|T_{1}^{t}\right\|^{1 / p}\right)\left(\left\|T_{1}^{t}\right\|^{1-(1 / p)}-\left\|T_{1}\right\|^{1-(1 / p)}\right) \\
& =-\left\|T_{1}\right\|-\left\|T_{1}^{t}\right\|+\left\|T_{1}\right\|^{1 / p}\left\|T_{1}^{t}\right\|^{1-(1 / p)}+\left\|T_{1}\right\|^{1-(1 / p)}\left\|T_{1}^{t}\right\|^{1 / p},
\end{aligned}
$$

whence

$$
\left\|T_{1}\right\|^{1 / p}\left\|T_{1}^{t}\right\|^{1-(1 / p)}+\left.\left\|T_{1}\right\|^{1-(1 / p)}\left\|T_{1}^{t}\right\|\right|^{1 / p}<\left\|T_{1}\right\|+\left\|T_{1}^{t}\right\| .
$$

Using these inequalities together with the fact that 


$$
\left|\sigma\left(T_{p}+\bar{T}_{p}^{t}\right)\right| \leqq\left\|T_{p}+\bar{T}_{p}^{t}\right\|
$$

we see that

$$
\left|\sigma\left(T_{p}+\bar{T}_{p}^{t}\right)\right|<\left\|T_{1}+\bar{T}_{1}^{t}\right\| .
$$

It is obvious that the operator

$$
\frac{T_{1}+\bar{T}_{1}^{t}}{\left\|T_{1}+T_{1}^{t}\right\|}
$$

is regular and thus

$$
\left|\sigma\left(T_{1}+\bar{T}_{1}^{t}\right)\right|=\left\|T_{1}+\bar{T}_{1}^{t}\right\| .
$$

This with the last inequality implies the desired conclusion,

$$
\left|\sigma\left(T_{p}+\bar{T}_{p}^{t}\right)\right|<\left|\sigma\left(T_{1}+\bar{T}_{1}^{t}\right)\right| \text {. }
$$

THEOREM 3. Suppose $T=\left(t_{i j}\right)$ defines an element of $\left[l_{1}\right], t_{i j}$ is positive for all $i$ and $j$, and the infimum of the column sums of $T$ is greater than $\left\|T_{p}\right\|$. Then $\left|\sigma\left(T_{p}\right)\right|<\left|\sigma\left(T_{1}\right)\right|$.

Proof. Let $T^{n}=\left(t_{i j}^{(n)}\right), n>1$. By hypothesis $\inf _{j} \sum_{i=1}^{\infty} t_{i j}=K>\left\|T_{p}\right\|$. If $\inf _{j} \sum_{i=1}^{\infty} t_{i j}^{(n)} \geqq K^{n}$, then

$$
\begin{aligned}
\inf _{j} \sum_{i=1}^{\infty} t_{i j}^{(n+1)} & =\inf _{j} \sum_{i=1}^{\infty} \sum_{k=1}^{\infty} t_{i k}^{(n)} t_{k j}=\inf _{j}\left(\sum_{k=1}^{\infty} t_{k j} \sum_{i=1}^{\infty} t_{i k}^{(n)}\right) \\
& \geqq \inf _{j} \sum_{k=1}^{\infty} t_{k j} K^{n}=K^{n+1} .
\end{aligned}
$$

Thus by induction we have $\inf _{j} \sum_{i=1}^{\infty} t_{i j}^{(n)} \geqq K^{n}$ for all $n$. It follows that $\left\|T_{1}^{n}\right\| \geqq K^{n}$ for all $n$, whence

$$
\left|\sigma\left(T_{1}\right)\right| \geqq K>|| T_{p} \| \geqq\left|\sigma\left(T_{p}\right)\right|,
$$

and our theorem is proved.

Final Remarks. Matrices satisfying the hypotheses of the above theorems are easily constructable. The matrix $T=\left(t_{i j}\right)$,

$$
t_{i j}=\left\{\begin{array}{cl}
j /(i-1) i & \text { if } i>j \\
0 & \text { if } i \leqq j
\end{array}\right.
$$

cited in [1], satisfies the hypotheses of each of theorems (where in particular $p=2$ in Theorem 3).

That the set of matrices satisfying the hypotheses of any one of these theorems forms a semigroup is a simple matter of computation. 


\section{BIBLIOGRAPHY}

1. Charles J. A. Halberg, Jr. and Angus E. Taylor, On the spectra of linked operators, Pacific J. Math., 6 (1956), 283-290.

2. C. J. A. Halberg, Jr., The spectra of bounded linear operators on the sequence spaces, Proc. Amer. Math. Soc., 8 (1957), 728-732.

UNIVERSITY OF CALIFORNIA, RIVERSIDE, AND

KøbenhavNs Universitets Matematiske Institut. 



\section{PACIFIC JOURNAL OF MATHEMATICS}

\section{EDITORS}

RalPh S. Phillips

Stanford University

Stanford, California

M. G. Arsove

University of Washington

Seattle 5 , Washington
J. Dugundu

University of Southern California

Los Angeles 7, California

Lowell J. Paige

University of California

Los Angeles 24, California

\section{ASSOCIATE EDITORS}
E. F. BECKENBACH
D. DERRY
H. L. ROYDEN
E. G. STRAUS
T. M. CHERRY
M. OHTSUKA
E. SPANIER
F. WOLF

\section{SUPPORTING INSTITUTIONS}

\author{
UNIVERSITY OF BRITISH COLUMBIA \\ CALIFORNIA INSTITUTE OF TECHNOLOGY \\ UNIVERSITY OF CALIFORNIA \\ MONTANA STATE UNIVERSITY \\ UNIVERSITY OF NEVADA \\ NEW MEXICO STATE UNIVERSITY \\ OREGON STATE UNIVERSITY \\ UNIVERSITY OF OREGON \\ OSAKA UNIVERSITY \\ UNIVERSITY OF SOUTHERN CALIFORNIA
}

\author{
STANFORD UNIVERSITY \\ UNIVERSITY OF TOKYO \\ UNIVERSITY OF UTAH \\ WASHINGTON STATE UNIVERSITY \\ UNIVERSITY OF WASHINGTON \\ AMERICAN MATHEMATICAL SOCIETY \\ CALIFORNIA RESEARCH CORPORATION \\ SPACE TECHNOLOGY LABORATORIES \\ NAVAL ORDNANCE TEST STATION
}

Mathematical papers intended for publication in the Pacific Journal of Mathematrcs should be typewritten (double spaced), and the author should keep a complete copy. Manuscripts may be sent to any one of the four editors. All other communications to the editors should be addressed to the managing editor, L. J. Paige at the University of California, Los Angeles 24, California.

50 reprints per author of each article are furnished free of charge; additional copses may be obtained at cost in multiples of 50 .

The Pacific Journal of Mathematics is published quarterly, in March, June, September, and December. Effective with Volume 13 the price per volume (4 numbers) is $\$ 18.00$; single issues, $\$ 5.00$. Special price for current issues to individual faculty members of supporting institutions and to individual members of the American Mathematical Society: $\$ 8.00$ per volume; single issues $\$ 2.50$. Back numbers are available.

Subscriptions, orders for back numbers, and changes of address should be sent to Pacific Journal of Mathematics, 103 Highland Boulevard, Berkeley 8, California.

Printed at Kokusai Bunken Insatsusha (International Academic Printing Co., Ltd.), No. 6 , 2-chome, Fujimi-cho, Chiyoda-ku, Tokyo, Japan.

\section{PUBLISHED BY PACIFIC JOURNAL OF MATHEMATICS, A NON-PROFIT CORPORATION}

The Supporting Institutions listed above contribute to the cost of publication of this Journal, but they are not owners or publishers and have no responsibility for its content or policies. 


\section{Pacific Journal of Mathematics}

\section{Vol. 13, No. $4 \quad$ June, 1963}

Dallas O. Banks, Bounds for eigenvalues and generalized convexity ........... 1031

Jerrold William Bebernes, A subfunction approach to a boundary value problem for

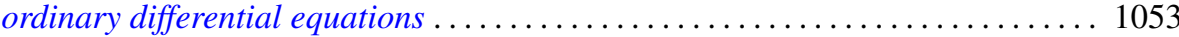

Woodrow Wilson Bledsoe and A. P. Morse, A topological measure construction . . . 1067

George Clements, Entropies of several sets of real valued functions . . . . . . . . . 1085

Sandra Barkdull Cleveland, Homomorphisms of non-commutative *-algebras . . . . . 1097

William John Andrew Culmer and William Ashton Harris, Convergent solutions of

ordinary linear homogeneous difference equations . . . . . . . . . . . . . . . 1111

Ralph DeMarr, Common fixed points for commuting contraction mappings . . . . . . 1139

James Robert Dorroh, Integral equations in normed abelian groups . . . . . . . . 1143

Adriano Mario Garsia, Entropy and singularity of infinite convolutions . . . . . . . 1159

J. J. Gergen, Francis G. Dressel and Wilbur Hallan Purcell, Jr., Convergence of extended Bernstein polynomials in the complex plane ................. 1171

Irving Leonard Glicksberg, A remark on analyticity of function algebras . . . . . . 1181

Charles John August Halberg, Jr., Semigroups of matrices defining linked operators

with different spectra ................................. 1187

Philip Hartman and Nelson Onuchic, On the asymptotic integration of ordinary

differential equations . . . . . . . . . . . . . . . . . . . . . . . . . . . . 1193

Isidore Heller, On a class of equivalent systems of linear inequalities . . . . . . . . . 1209

Joseph Hersch, The method of interior parallels applied to polygonal or multiply

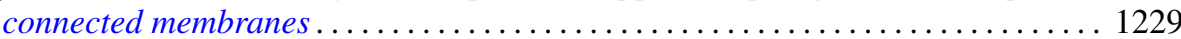

Hans F. Weinberger, An effectless cutting of a vibrating membrane . . . . . . . . . . 1239

Melvin F. Janowitz, Quantifiers and orthomodular lattices ....

Samuel Karlin and Albert Boris J. Novikoff, Generalized convex inequalities . .

Tilla Weinstein, Another conformal structure on immersed surfaces of negative

curvature.

Gregers Louis Krabbe, Spectral permanence of scalar operators

Shige Toshi Kuroda, Finite-dimensional perturbation and a representaion of

scattering operator.

Marvin David Marcus and Afton Herbert Cayford, Equality in certain

inequalities

Joseph Martin, A note on uncountably many disks .

Eugene Kay McLachlan, Extremal elements of the convex cone of semi-norms . . . . 1335

John W. Moon, An extension of Landau's theorem on tournaments . .

Louis Joel Mordell, On the integer solutions of $y(y+1)=x(x$

Kenneth Roy Mount, Some remarks on Fitting's invariants .....

Miroslav Novotný, Über Abbildungen von Mengen ............

Robert Dean Ryan, Conjugate functions in Orlicz spaces.

John Vincent Ryff, On the representation of doubly stochastic operators . . . . . . . . 1379

Donald Ray Sherbert, Banach algebras of Lipschitz functions .

James McLean Sloss, Reflection of biharmonic functions across analytic boundary

conditions with examples.

L. Bruce Treybig, Concerning homogeneity in totally ordered, connected topological space....

John Wermer, The space of real parts of a function algebra...

James Juei-Chin Yeh, Orthogonal developments of functionals and related theorems

in the Wiener space of functions of two variables......... 